\title{
Lime Oil
}

National Cancer Institute

\section{Source}

National Cancer Institute. Lime Oil. NCI Thesaurus. Code C107323.

The oil extracted from the fruit peel of Citrus aurantifolia. Lime oil can be taken as an antioxidant and may help support immune health. Additionally, it is used as a flavoring agent. 